Article

\title{
Fungal Interactions Matter: Tricholoma matsutake Domination Affect Fungal Diversity and Function in Mountain Forest Soils
}

\author{
Jie Zhou ${ }^{1,+}{ }^{\dagger}$ Heng Gui ${ }^{2,3,+} \mathbb{0}$, Shujiao Yang ${ }^{3}$, Xuefei Yang ${ }^{3,4,5, *}$ and Lingling Shi ${ }^{1,2}$ \\ 1 Biogeochemistry of Agroecosystems, Department of Crop Science, Georg August University of Göttingen, \\ 37075 Göttingen, Germany; jackzhou516@gmail.com (J.Z.); shilingling@mail.kib.ac.cn (L.S.) \\ 2 Centre for Mountain Futures (CMF), Kunming Institute of Botany, Kunming 650201, China; \\ guiheng@mail.kib.ac.cn \\ 3 Key Laboratory of Economic Plants and Biotechnology, Kunming Institute of Botany, Chinese Academy of \\ Sciences, Heilongtan, Kunming 650201, China; lingling.shi@uni-goettingen.de \\ 4 Southeast Asia Biodiversity Research Institute, Chinese Academy of Sciences, \\ Menglun, Mengla 666303, China \\ 5 Lijiang Forest Biodiversity National Observation and Research Station, Kunming Institute of Botany, \\ Chinese Academy of Sciences, Lijiang 674100, China \\ * Correspondence: xuefei@mail.kib.ac.cn \\ + These authors contribute equally to this work.
}

check for

updates

Citation: Zhou, J.; Gui, H.; Yang, S.; Yang, X.; Shi, L. Fungal Interactions Matter: Tricholoma matsutake Domination Affect Fungal Diversity and Function in Mountain Forest Soils. Biology 2021, 10, 1051. https:// doi.org/10.3390/biology10101051

Academic Editor: Maria Amélia Martins-Loução

Received: 6 September 2021

Accepted: 11 October 2021

Published: 15 October 2021

Publisher's Note: MDPI stays neutral with regard to jurisdictional claims in published maps and institutional affiliations.

Copyright: (c) 2021 by the authors. Licensee MDPI, Basel, Switzerland. This article is an open access article distributed under the terms and conditions of the Creative Commons Attribution (CC BY) license (https:// creativecommons.org/licenses/by/ $4.0 /)$.
Simple Summary: Tricholoma matsutake forms a symbiotic association with hosts, developing mycelial aggregations, called 'shiro'. The fungal diversity living in shiro soil play key roles in nutrient cycles for this economically important mushroom, but have not been profiled across large spatial and environmental gradients. Here, we mainly aimed to study the fungal characteristics in the bulk soil (non-shiro) and shiro, using phospholipid fatty acids and illuninan sequencing in five habitats across landscapes in southwestern China. T. matsutake causes a lower fungal diversity and simplifies the fungal community composition in shiro soil compared with non-shiro soil across five forest types. We also found that geo-graphical proximity was accompanied by a similar fungal community structure but different contributions from specific species under five forest types. Among the co-existed fungi, Oidiodendron were found to collaborate with T. matsutake, whereas Helotiales and Mortierella showed a negative correlation with it. The selection of these taxa may be related to their ability to compete with resources and different nutrient strategists in the soil. Overall, we conclude that $\mathrm{T}$. matsutake generate a dominance effect to shape the fungal community and diversity in shiro soil across distinctive forest types.

Abstract: Tricholoma matsutake forms a symbiotic association with coniferous trees, developing mycelial aggregations, called 'shiro', which are characterized by distinct chemical and physical properties from nearby forest bulk soil. The fungal diversity living in shiro soil play key roles in nutrient cycles for this economically important mushroom, but have not been profiled across large spatial and environmental gradients. Samples of shiro and non-shiro (nearby bulk soil) were taken from five field sites where sporocarps naturally formed. Phospholipid fatty acids (PLFA) and Illumina MiSeq sequencing were combined to identify fungal biomass and community structure. Matsutake dominated in the shiro, which had a significantly reduced saprotrophic fungi biomass compared to non-shiro soil. Fungal diversity was negatively correlated with the relative abundance of T. matsutake in the shiro soil. The fungal community in the shiro was characterized by similar fungal species composition in most samples regardless of forest types. Matsutake coexisted with a specific fungal community due to competition or nutrient interactions. Oidiodendron was positively correlated with the abundance of T. matsutake, commonly cohabitant in the shiro. In contrast, Helotiales and Mortierella were negatively correlated with T. matsutake, both of which commonly inhabit the non-shiro soil but do not occur in shiro soils. We conclude that T. matsutake generate a dominance effect to shape the fungal community and diversity in shiro soil across distinctive forest types. 
Keywords: Tricholoma matsutake; shiro; fungal community; ectomycorrhizal fungi

\section{Introduction}

Tricholoma matsutake (S. Ito et Imai) is an ectomycorrhizal (ECM) fungi that forms symbiosis with Pinaceae and Fagaceae in regions such as China, Korea, and the Northern Hemisphere [1,2]. Matsutake can colonize plants in the rhizosphere, and develops a mycelial aggregation associated with their host roots and soil particles, named 'shiro' soil [1]. This unique and massive mycorrhizal mycelial aggregate generally forms $5-20 \mathrm{~cm}$ deep in mineral soil, which is visually distinct from the surrounding soil $[3,4]$. Fruiting bodies are formed in the shiro soil, where they can extract water and nutrients, therefore, a better understanding of the biotic and abiotic properties of shiro soil is crucial to T. matsutake production.

Interactions of microbial communities with T. matsutake in terrestrial environments have been widely studied, however, these studies have revealed divergent strategies [3-6]. For example, Lian et al. (2006) indicated that lower fungal diversity was found beneath the shiro in comparison to other zones (i.e., inside and outside the shiro) [3], which may be due to T. matsutake domination $[7,8]$. By contrast, Kim et al. (2013) found no difference in bacterial diversity between shiro and non-shiro soil [6]. Overall, T. matsutake seems to impart strong selection impacts on other microbial groups in the shiro soil.

T. matsutake domination generates unique physical and chemical properties of shiro soil, including a sandy texture, low $\mathrm{pH}$ and water holding capacity, which might indirectly affect the distinct soil microbial community $[9,10]$. The microbial groups in shiro soil may be important for the growth of T. matsutake [11], especially the existence of other soil fungi. Similar to T. matsutake, other mycorrhizal fungi play essential roles in carbon (C) and nutrient processes in terrestrial ecosystems [12]. However, T. matsutake commonly competes with other soil fungi for nutrients and living space [13,14], and then suppresses them with chemicals released from its hyphae, such as organic acids, lipids and special metabolites [15]. Conversely, some saprotrophic fungi may feed on mycorrhizal hyphae, consequently affecting its growth [14]. Therefore, future research on the interactions between soil fungal communities and T. matsutake in shiro soil are important for understanding how various fungi coexist with T. matsutake.

The soil microbial community is governed in part by the edaphic characteristic of the soil and aboveground plants, the regional climate conditions, and the interactions between these factors [16,17]. Importantly, plant types provide soils with abundant $C$ and energy resources (i.e., rhizodepositions), thus exerting important and persistent effects on the formation of soil physic-chemical environments, and consequently selecting for specific soil microbial communities $[18,19]$. Here, we mainly aimed to study the fungal characteristics in the bulk soil (non-shiro) and shiro of T. matsutake combined, using phospholipid fatty acids (PLFA) and illuninan sequencing in variable habitats across landscapes in southwestern China. We hypothesized that: (1) T. matsutake has remarkable influences within the rhizosphere microbiome and shows different patterns between shiro and non-shiro soil due to the selection effect of T. matsutake [15]; (2) fungal community structure in the shiro dominated with T. matsutake across forest types show a similarity due to the domination effect of T. matsutake.

\section{Methods and Materials}

\subsection{Site Description and Soil Sampling}

Five annual Tricholoma produced forests were chosen in Yunnan, South-western China: Deqing (DQ1, DQ2), Lijing (LJ), Baoshan (BS) and Chuxiong (CX) (Table 1; Figure S1). Tricholoma are the major source of mushroom production in these areas. At each site, five random field replicate plots of $20 \mathrm{~m} \times 20 \mathrm{~m}$ were set, which were separated with $25 \mathrm{~m}$ intervals. Here, we only set three field replicates in BS which was dominated with 
Pine. After removing the humus, soils were taken from the upper $10 \mathrm{~cm}$ in a fairy ring area (beneath the Tricholoma) on September 2015 with a soil drill during the mushroom harvesting season. In each of the five field replicates at each forest site, three sub-samples were mixed to form a homogeneous soil sample. The shiro areas at each forest site were $2 \mathrm{~m}$ away from each other. Another five sub-samples taken randomly inside each plot which were at least $5 \mathrm{~m}$ away from the shiro area were corrected as non-shiro soil. The front end of the shiro where the Tricholoma matsutake hyphae dominated was carefully selected according to morphological characteristics, where shiro has a significantly different sandy soil texture compared to the background soil. Once collected, samples were mixed, and any visible roots and stones manually removed. Soils were stored in sterile sealed bags on ice and then transported to laboratory to store under $-20^{\circ} \mathrm{C}$. The relative abundance of genus Tricholoma in shiro soil was more than $40 \%$ of the whole community genotypes, significantly higher than that in the non-shiro soil (Figure S2). However, the relative abundance of Tricholoma varied with sites, with the highest relative abundance in DQ2 (>45\%) and lowest in BS (20\%). The composition of Tricholoma was simple, where $90 \%$ of the OTUs were classified as Tricholoma sp. Additionally, Tricholoma was the biggest ectomycorrhizal fungal group in this area (Table 1).

Table 1. Site and stand characteristics of the study sites Deqing (DQ1, DQ2), Lijing (LJ), Baoshan (BS) and Chuxiong (CX).

\begin{tabular}{|c|c|c|c|c|c|}
\hline Stand Parameters & DQ1 & DQ2 & LJ & BS & $\mathrm{CX}$ \\
\hline Coordinates & $28^{\circ} 05^{\prime} \mathrm{N}, 99^{\circ} 37^{\prime} \mathrm{E}$ & $28^{\circ} 04^{\prime} \mathrm{N}, 99^{\circ} 38^{\prime} \mathrm{E}$ & $27^{\circ} 00^{\prime} \mathrm{N}, 100^{\circ} 10^{\prime} \mathrm{E}$ & $25^{\circ} 16^{\prime} \mathrm{N}, 9^{\circ} 18^{\prime} \mathrm{E}$ & $25^{\circ} 10^{\prime} \mathrm{N}, 101^{\circ} 00^{\prime} \mathrm{E}$ \\
\hline Altitude (m a.s.l) & 3747 & 3452 & 3346 & 2452 & 2486 \\
\hline $\begin{array}{c}\text { Annual mean } \\
\text { temperature }\left({ }^{\circ} \mathrm{C}\right)\end{array}$ & 7.3 & 7.3 & 9.0 & 17.3 & 17.6 \\
\hline $\begin{array}{c}\text { Annual mean } \\
\text { Precipitation }(\mathrm{mm})\end{array}$ & 638 & 638 & 1275 & 600 & 1125 \\
\hline Tree species & $\begin{array}{c}\text { Quercus } \\
\text { Semecarpifolia }\end{array}$ & Pinus densata & $\begin{array}{l}\text { Pinus yunnanensis, } \\
\text { Quercus guyavefolia }\end{array}$ & $\begin{array}{c}\text { Pinus armandii } \\
\text { Franch, } \\
\text { Pinus yunnanensis }\end{array}$ & Pinus yunnanensis \\
\hline
\end{tabular}

\subsection{Soil and Plant Characterization}

Total carbon $(\mathrm{C})$ and total nitrogen $(\mathrm{N})$ were determined by an elemental analysis (LECO CNS 2000, Leco Corporation, Joseph MI, USA). Soil pH was measured in suspension with a soil to water $(\mathrm{m} / \mathrm{w})$ ratio of 1:2.5 with a portable $\mathrm{pH}$ meter $(\mathrm{HI} 99121 \mathrm{~N}$, Hanna Instruments, Beijing, China), and total phosphorus $(\mathrm{P})$ concentration was determined by ICP-MS analysis (Spectro, Kleve, Germany). Plant investigations were performed in each field plot, including plant species identification (species composition, diversity and ectomycorrhizal host species), shrub and grass coverage. Here, the dominant ectomycorrhizal host tree species were pine.

\subsection{Phospholipid-Fatty Acid Analysis}

Phospholipid fatty acids (PLFAs) were analyzed according to the protocol described by Frostegård et al. (1993) [19]. Briefly, $8 \mathrm{~g}$ of soil was extracted with a one-phase mixture of chloroform, methanol, and aqueous citric acid (1:2:0:8, $v / v / v, \mathrm{pH} 4.0)$ with two extraction steps. Phospholipids were separated from neutral lipids and glycolipids by solid phase extraction using an activated Silica gel (Silica gel Merck, particle size 0.063-0.200 mm). Then, phospholipids were analyzed with an Agilent 6890 gas chromatograph equipped with a flame ionization detector and an Ultra-2 column. The following PLFA biomarker were quantified into respective soil fungal groups: arbuscular mycorrhizal (AM) fungi was identified as $16: 1 \omega 5 \mathrm{c}$, saprotrophic (SAP) fungi was identified by 18:2w6, 9, and ectomycorrhizal (ECM) fungi was identified by the sum of $18: 1 \omega 9 \mathrm{c}$, and $18: 3 \omega 6,9,12 \mathrm{c}$ [20]. 


\subsection{DNA Amplicon and Illumina Sequencing of Fungal Communities}

The primer ITS3_KYO2(5'-GATGAAGAACGYAGYRAA-3') and ITS4-Barcodes (5'-TCCTCCGCTTATTGATATGC-3') were used to amplify the ITS special region for mycorrhizal fungi. Amplifications were prepared using DNA (50 ng), as well as $0.5 \mathrm{mM}$ each of forward and reverse primers in a $25 \mathrm{ul}$ volume. PCR reactions were conducted under $94{ }^{\circ} \mathrm{C}$ for $5 \mathrm{~min}$, then cycled 35 times under $94{ }^{\circ} \mathrm{C}$ for $30 \mathrm{~s}$, followed by $30 \mathrm{~s}$ under $53{ }^{\circ} \mathrm{C}$ and $50 \mathrm{~s}$ under $72^{\circ} \mathrm{C}$, annealing three times under $53^{\circ} \mathrm{C}$, with a final elongation conducted under $72{ }^{\circ} \mathrm{C}$ for $5 \mathrm{~min}$. PCR was purified with SanPrep DNA Gel Extraction Kit. After quantifying PCR with a Thermo Scientific ${ }^{\mathrm{TM}}$ NanoDrop ${ }^{\mathrm{TM}}$. PCR products were mixed homogeneously. The library was built using TruSeq ${ }^{\circledR}$ DNA PCR-Free Sample Preparation Kit. After qualification by Qubit and qPCR, the DNA were sequenced using a v2 sequencing kit $(2 \times 250 \mathrm{bp})$ to perform Illumina sequencing on Miseq (high-though sequencing planform of Chengdu Institute of Biology, CAS).

The sequencing data were analysis by QIIME (v1.9.0). The noise reduction was performed using Denoiser 0.851 and Uchime, and chimeric sequences were detected using UCHIME and deleted. Sequences were shortened to 300 base pairs, and any sequences shorter than 300 base pairs were removed. Fungal sequences were independently clustered using USEARCH at $97 \%$ similarity. These sequences were then clustered into operation units (OTUs) using the UPARSE algorithm. The centroid sequence from each cluster is then run against either the USEARCH global alignment algorithm or against a database of high-quality sequences derived from the NCBI database. In total, 1395 OTUs were identified in all samples. The output was then analyzed using an internally developed python program that assigns taxonomic information to each sequence and then computes and writes the final analysis files. Based on the FUNGuild database 1.0, fungal OTUs were assigned to functional groups [21,22], which were performed at genus level, and only assignments with confidence levels of "highly probable" or "probable" were kept for further analyses. About $60 \%$ of the OTUs were matched to a functional guild in the FUNGuild database. The relative abundance of each functional group was similar with the sum of the relative abundance of all OTUs having a particular functional group.

\subsection{Statistical Analysis}

All the data sets were simplified to 6341 per sample by using the function "rarefy" in the $\mathrm{R}$ package vegan. Soil fungi richness analyses was performed by counting the OTU richness and standardized OTU richness with the function "diversity" and "scale" in the R package vegan, respectively. A Venn plot was created using 'Calculate and draw custom Venn diagrams' to differentiate between unique and shared OTUs dependent on feeding strategy. To evaluate the extent to which the individual OTU changes the way they interact with other OTUs in the network, significant co-presences or exclusions across the samples were identified by the CoNet method using a multiple ensemble correlation (guessing pair $=50$, row_minocc filter $=10$ ). Similarity measures were determined using Pearson and Spearman rank correlations. A co-occurrence network model was displayed by Cytoscape52, which indicated the interactions between fungal species. Nonmetric multidimensional scaling (NMDS) was performed to evaluate fungal community composition along the soil profile, as well as the correlation between fungal community structure and environmental factors (i.e., plant richness and diversity, as well as soil basic properties) based on the Bray-Curtis distances of the sequencing data using the vegan package. Twoway ANOVA was used to evaluate the effect of shiro and forest types on soil chemical properties. One-way ANOVA was used to evaluate the effect of shiro on specific microbial groups (ectomycorrhizal, saprotrophic and arbuscular mycorrhizal fungi biomass), fungi diversity and fungal richness with different trophic strategies across all forest sites, as well as the effect of forest types on plant diversity and richness. Permutational multivariate analysis of variance (PERMANOVA) was used to determine the effect of shiro and forest types on fungal community composition (OTUs). All statistical analyses were carried out with the R software v3.4.3. 


\section{Results}

\subsection{Characteristics of Soil in Tricholoma matsutake Fairy Ring}

T. matsutake fairy rings were generally down to a depth of $15 \mathrm{~cm}$, with a remarkable sandy texture distinct from the soils outside the fairy ring. Soil $\mathrm{pH}$, total $\mathrm{C}, \mathrm{N}$, and $\mathrm{P}$ varied with forest types $(p<0.01)$, but most of them showed generally similarity between shiro and non-shiro soils irrespective of forest types ( $p>0.05$; Figure 1$)$. TN was $25 \%$ lower in shiro than that in non-shiro soil (1.54 vs. $\left.1.93 \mathrm{~g} \mathrm{~kg}^{-1}, p<0.05\right)$, thus, it caused a higher C:N ratio in shiro compared with non-shiro soil $(p<0.05$, Figure 1$)$.
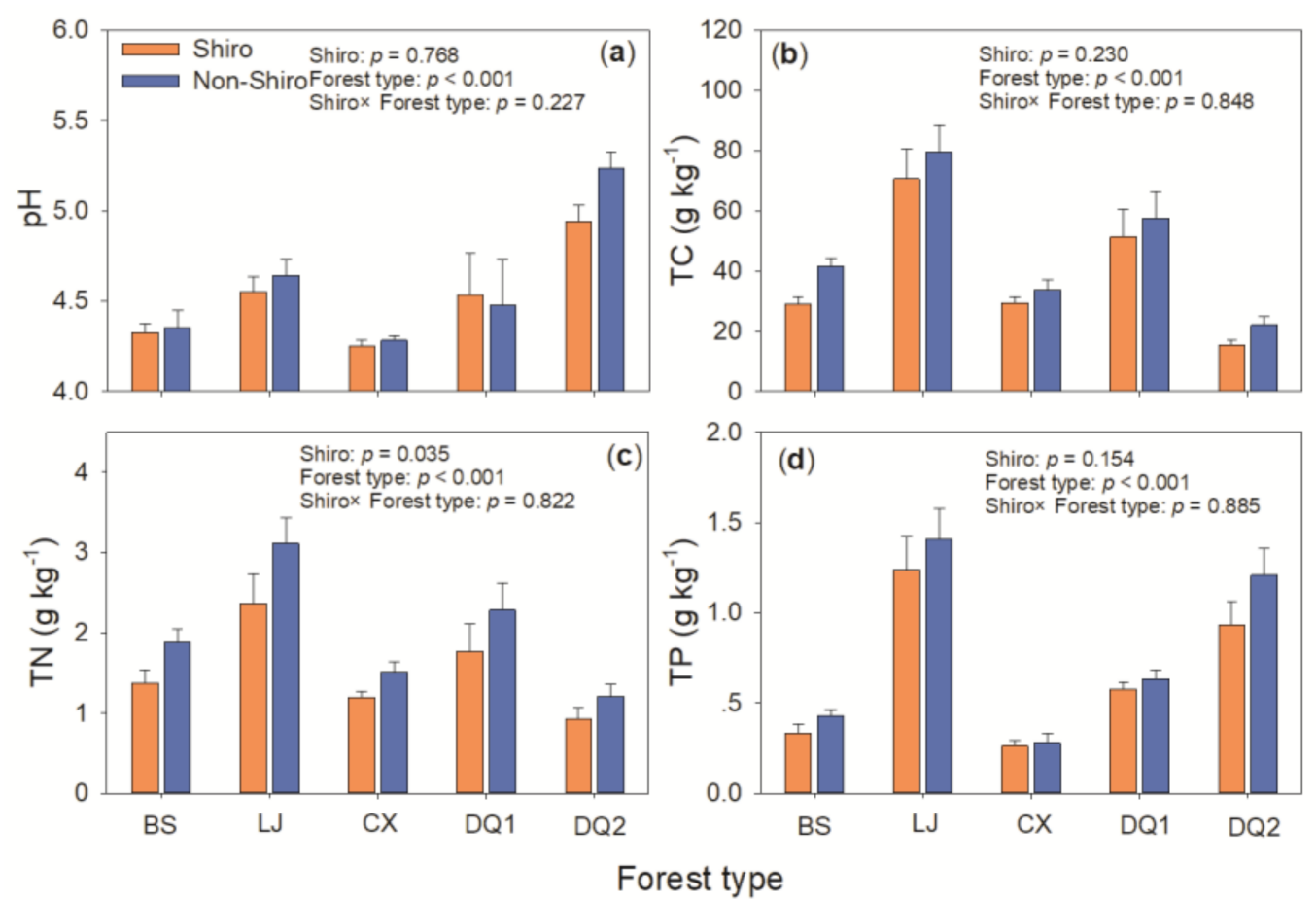

Figure 1. Soil pH (a), total carbon TC (b), total nitrogen TN (c), and total phosphorus TP (d) in the shiro and bulk soil from Deqing (DQ1, DQ2), Lijing (LJ), Baoshan (BS) and Chuxiong (CX) in Yunnan, South-western China.

\subsection{Fungal PLFA Biomass}

Microbial total PLFAs biomass were significantly higher in shiro than in non-shiro soil, due to an average $10 \%$ more fungal biomass in shiro (data not shown). Shiro soil contained $80 \%$ fungal biomass belonging to ECM fungi, with a lower biomass of AM fungi and SAP fungi $(<10 \%)$. In terms of fungal group biomarkers, ECM and AM fungi were 180 and $450 \mathrm{nmol} \mathrm{g}^{-1}$ soil higher in the shiro compared with non-shiro soil, whereas the SAP fungi biomass was $120 \mathrm{nmol} \mathrm{g}^{-1}$ soil lower in shiro than in non-shiro soil across all forest sites $(p<0.05$, Figure $2 b)$. 

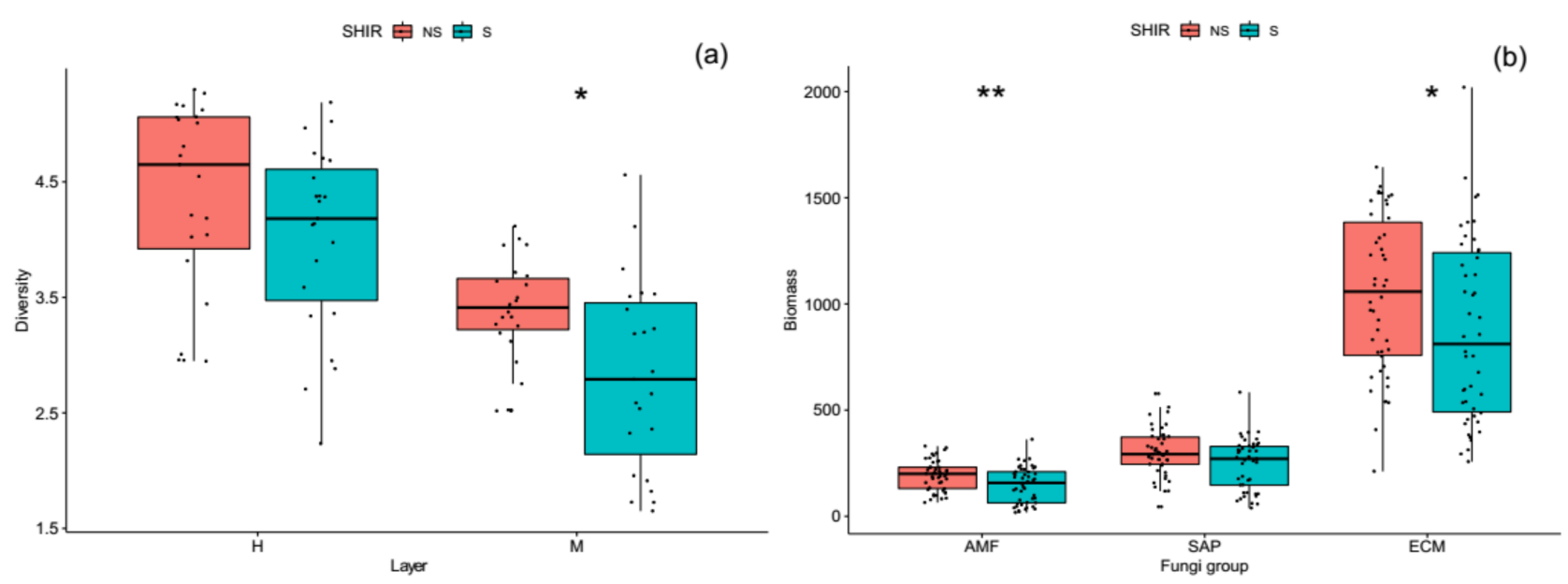

$\mathrm{NS} / \mathrm{S}$

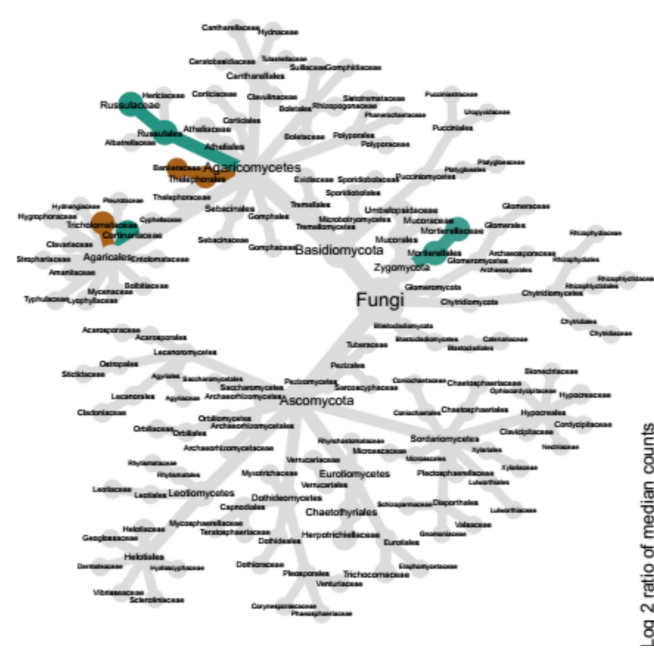

(c)

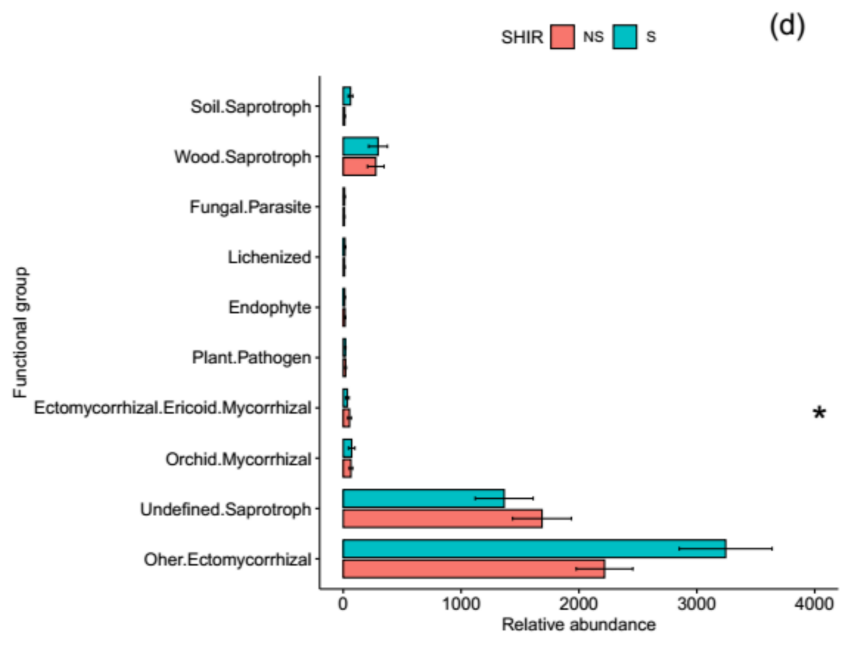

Figure 2. The changes of specific microbial groups based on, fungal diversity (a), phospholipid-fatty acid (b), fungi community composition (c), and their functions (d) in the shiro and non-shiro soil from all forest sites. ${ }^{*}$ and ${ }^{* *}$ indicate the significant differences between shiro and non-shiro soils at $p<0.05$ and $p<0.01$, respectively.

\subsection{Fungal Diversity, Species Composition and Functional Profiles}

The fungal diversity in shiro was $29 \%$ lower than that of non-shiro soil (1.4 vs. 1.8, Figure 2a), with lower fungal richness in shiro than in non-shiro soil, whereas there was no difference between forest types ( $p>0.05$, Table S2). The Pielou evenness index, indicating the distribution of each species in a community, indicated that shiro soil had a relatively uneven distribution compared with non-shiro soil $(p<0.001)$. The low fungal diversity results from shiro soil (the mycorrhizal zone for fruiting bodies) were considered due to the predominance of T. matsutake (Figure S2). Therefore, the farther away the forest soil fungal communities were from the fairy ring, the more diverse was their composition, indicating a negative correlation between fungal diversity and the relative abundance of Tricholoma observed $\left(R^{2}=0.63\right.$, Figure 3$)$.

Members of the genera Lactarius dominated in the shiro soil, followed by Russula, Amarita, and Boletopsis, whereas the relative abundance of Lyophyllum, Clayulina, Sarcodon, and Ramaria were higher in the non-shiro soil compared with shiro $(p<0.05$, Figure 2c). After classifying the taxa to fungal gilds, SAP fungi (e.g., wood and soil saprotroph, ecmsap) fungi was $1 \mathrm{x}$ lower in shiro compared to non-shiro soil ( $p<0.05$, Figure $2 \mathrm{~d})$. Similarly, other ECM fungi were decreased by $47 \%$ in shiro compared to non-shiro soil. In terms of trophic strategies of each fungal taxon, however, there were no differences in total fungi 
and SAP fungal species richness between shiro and non-shiro soil ( $p>0.05$, Table S3), whereas the richness of ECM fungi was $27 \%$ lower in shiro compared with non-shiro soil.

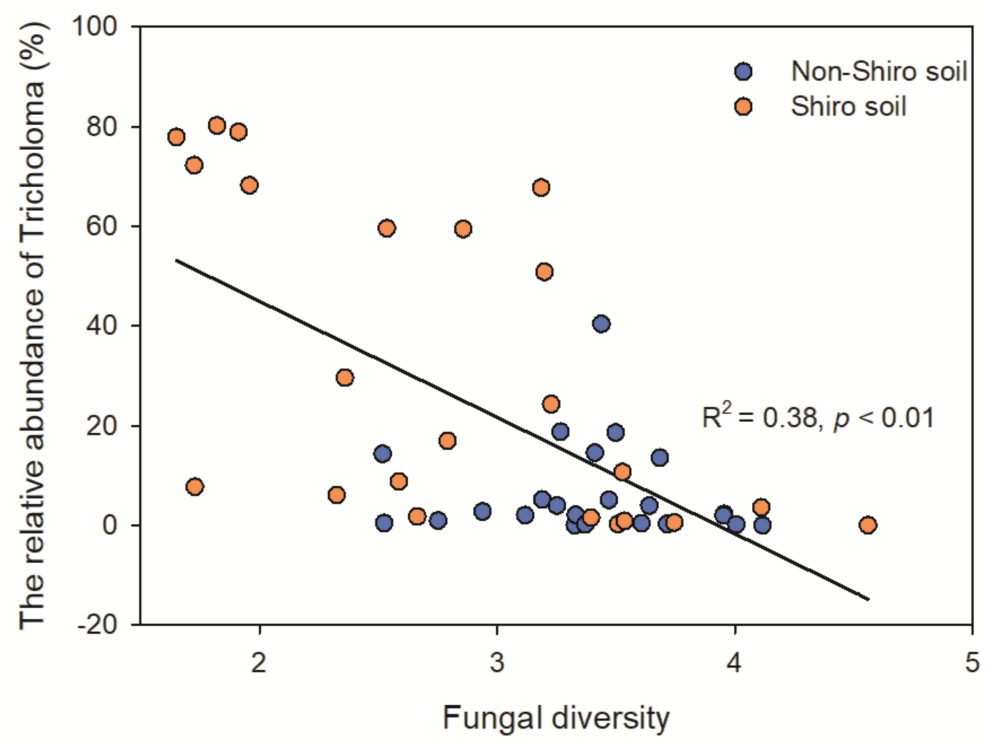

Figure 3. The correlation between fungal diversity and the relative abundance of Tricholoma both in the shiro and non-shiro soil from Deqing (DQ1, DQ2), Lijing (LJ), Baoshan (BS) and Chuxiong (CX).

NMDS ordination of the fungal community did not completely separate shiro and nonshiro samples (Figure S3a), but samples from forest types tended to separate in different clusters along axis 1 (Figure S3b). Further, the fungal community structure in shiro soils was not only affected by soil properties (e.g., pH, TC, TN and TP), but was also affected by the diversity and richness of tree as well as its' ECM host trees across different forest types $(p<0.05$, Table S2).

\subsection{The Correlation between Tricholoma and Other Soil Fungi in the Shiro Soil}

In total, $78 \%$ of soil fungi was negatively correlated with Tricholoma. However, all the soil fungi were negatively correlated with Tricholoma in DQ1 and DQ2, whereas the positive correlation between soil fungi and Tricholoma was only found in BS, CX and LJ. At genus levels, however, there were similar soil fungi that correlate with Tricholoma across forest types, such as Mortierella and Helotiales which was negatively correlated with Tricholoma, whereas Oidiodendron was correlated with Tricholoma (Figure 4; Table 2).

Table 2. The correlation between T.matsutake and other fungi groups. The + indicates positive correlation, whereas indicates negative correlation.

\begin{tabular}{|c|c|c|c|}
\hline & Mortierella - & Helotiales - & Oidiodendron + \\
\hline \multirow[t]{2}{*}{ BS } & $\begin{array}{l}\text { Mortierella amoeboidea } \\
\text { Mortierella humilis }\end{array}$ & OTU_97 & Oidiodendron chlamydosporicum \\
\hline & Mortierella humilis & OTU_957 & Oidiodendron griseum \\
\hline $\mathrm{CX}$ & $\begin{array}{l}\text { Mortierella cystojenkinii } \\
\text { OTU } 119\end{array}$ & $\begin{array}{l}\text { OTU_597 } \\
\text { OTU } 787\end{array}$ & Oidiodendron sp GK_2010 \\
\hline DQ1 & $\begin{array}{c}\text { Mortierella humilis } \\
\text { Mortierella sp WD32A } \\
\text { OTU_454 }\end{array}$ & OTU_33 & \\
\hline DQ2 & $\begin{array}{l}\text { Mortierella amoeboidea } \\
\text { Mortierella humilis }\end{array}$ & OTU_33 & Oidiodendron griseum \\
\hline LJ & OTU_3 & OTU_475 & \\
\hline
\end{tabular}




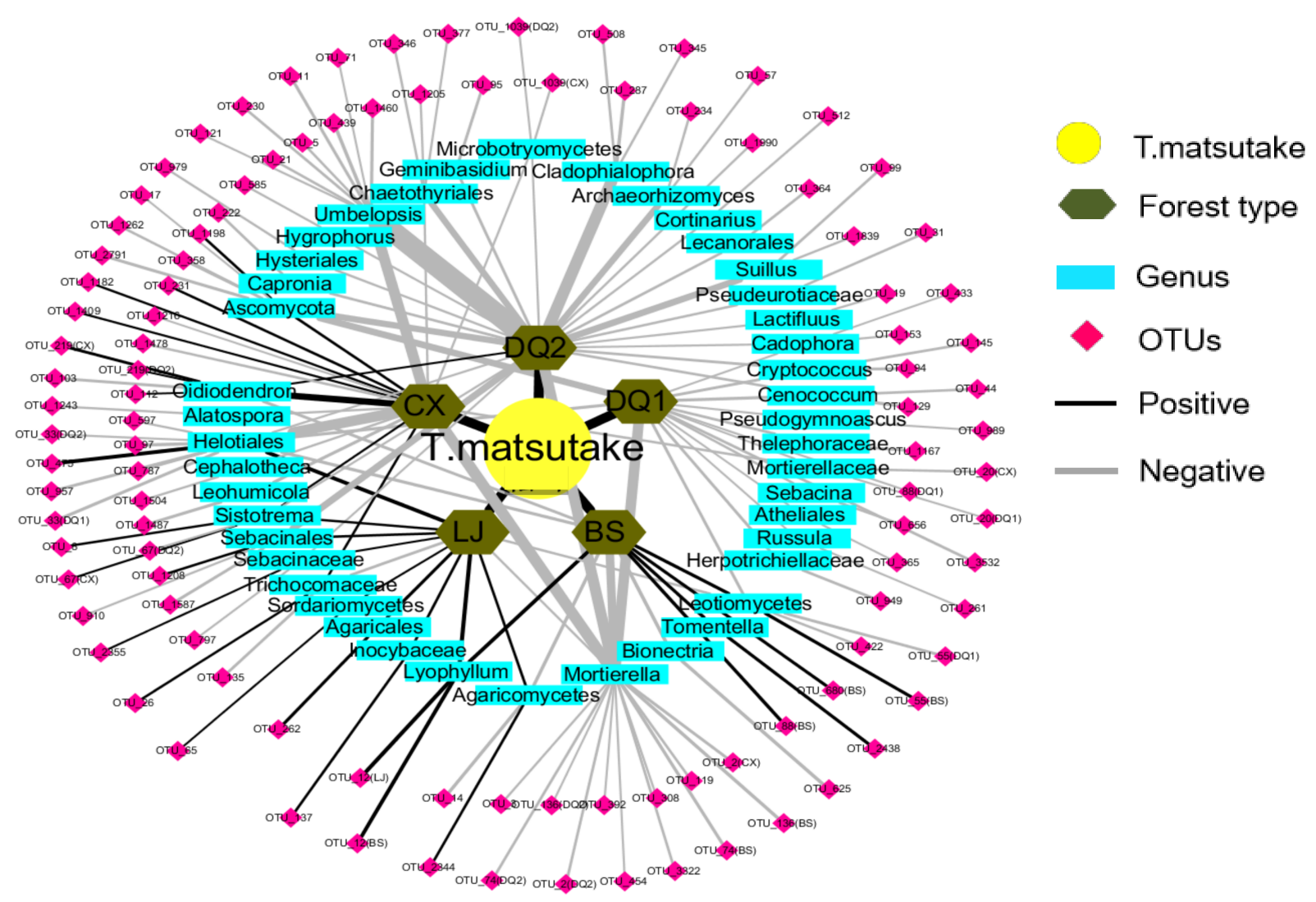

Figure 4. Correlation network of T.matsutake and other soil fungi in the shiro soil Figure 1. DQ2), Lijing (LJ), Baoshan (BS) and Chuxiong (CX) based on Spearman correlation analysis. The thickness of line indicates the $\mathrm{R}^{2}$ value.

\section{Discussion}

\subsection{Variations of Fungal Community Differences between Shiro and Non-Shiro Soil}

In the shiro soil, a significantly increased mycorrhizal fungal biomass (i.e., ECM and AM fungi) but reduced SAP fungal biomass compared with non-shiro soil was observed, which had some differences with previous studies. The increased mycorrhizal biomass was both due to ECM fruit body and AM fungi. AM fungi have their own $\mathrm{C}$ recourse from host roots [23,24], which might avoid competition with ECM fungi for $C$ and energy. Given that AM fungi plays an essential role in environments with less nutrients (i.e., $\mathrm{N}$ and $\mathrm{P}$ ) [25,26], the $\mathrm{P}$ limitation caused by T. matsutake immobilization may form an alternative explanation for the growth of AM fungi [27]. This was supported by the relative lower TP content in the shiro compared with non-shiro soil (Figure 1d). ECM fungi can capture nutrients released from decomposition by SAP fungi [28], and thus profit from their energy and C investment into enzyme activity. Furthermore, ECM fungi were found to release antibiotics that defend against saprotrophic activities under some conditions [29]. Therefore, the inhibition of growth and biomass of SAP fungi was observed in the shiro of T. matsutake.

To further investigate the fungal community composition, pyrosequencing was used, and a significant lower fungal diversity, as well as a lower ECM fungi richness, was observed (Figure 2), which was supported by previous studies [3,8]. Similar to other ECM fungi, T. matsutake can secrete antifungal substrates to inhibit other fungi, stimulating its own quantity and quality by decreasing competitors for nutrients and space [30]. This was further supported by the negative correlation between fungal diversity and the relative abundance of T. matsutake (Figure 3). On the other hand, soil properties were altered due to the uptake of nutrients or the exudation by T. matsutake in the shiro soil. In line with this, TN decreased in the shiro compared with non-shiro soil (Figure 1), and thus caused a shift in the fungal abundance and diversity between shiro and non-shiro soil (Figure 2; 
Table 3). Furthermore, host trees may indirectly shape soil fungal community composition because of their ability to alter the abiotic conditions in the surroundings [31]. Importantly, there was a significant relationship between the diversity of ECM colonized trees and fungal community structure (Table 3 ), due to their larger dependence on plant-microbe interactions as well as products of rhizodeposition [32].

Table 3. Relationship of soil and plant variables with soil fungal community structure.

\begin{tabular}{ccccccccc}
\hline \multirow{2}{*}{ Variables } & \multicolumn{4}{c}{ Shiro Soil } & \multicolumn{5}{c}{ Non-Shiro Soil } \\
\cline { 2 - 9 } & NMDS1 & NMDS2 & $\mathbf{R}^{\mathbf{2}}$ & $\mathbf{P}$ & NMDS1 & NMDS2 & $\mathbf{R}^{\mathbf{2}}$ & $\mathbf{P}$ \\
\hline pH & 0.181 & 0.983 & 0.497 & 0.001 & 0.449 & -0.893 & 0.067 & 0.241 \\
TC & 0.994 & -0.112 & 0.274 & 0.001 & 0.199 & 0.979 & 0.326 & 0.002 \\
TN & 0.969 & -0.245 & 0.282 & 0.001 & 0.163 & 0.986 & 0.297 & 0.003 \\
TP & 0.617 & 0.786 & 0.251 & 0.002 & 0.139 & 0.990 & 0.036 & 0.482 \\
Tree_H & -0.434 & -0.901 & 0.173 & 0.017 & -0.074 & 0.997 & 0.001 & 0.665 \\
Tree_S & -0.466 & -0.885 & 0.188 & 0.012 & 0.600 & -0.799 & 0.001 & 0.972 \\
dbh & 0.077 & -0.997 & 0.003 & 0.950 & -0.291 & 0.956 & 0.019 & 0.665 \\
high & 0.479 & 0.877 & 0.022 & 0.626 & 0.434 & -0.901 & 0.008 & 0.803 \\
Shrub_H & -0.269 & -0.962 & 0.041 & 0.408 & 0.322 & 0.946 & 0.039 & 0.401 \\
Shrub_S & -0.494 & -0.869 & 0.054 & 0.832 & 0.009 & 0.999 & 0.046 & 0.337 \\
Grass_H & -0.135 & 0.991 & 0.009 & 0.832 & 0.133 & 0.991 & 0.056 & 0.279 \\
Grass_S & -0.017 & 0.999 & 0.108 & 0.076 & -0.026 & 0.999 & 0.109 & 0.087 \\
ECMtree_H & -0.319 & -0.947 & 0.259 & 0.001 & -0.981 & 0.195 & 0.001 & 0.978 \\
ECMtre_S & -0.316 & -0.948 & 0.335 & 0.002 & -0.230 & 0.973 & 0.002 & 0.966 \\
\hline
\end{tabular}

As shown in the shiro soil, lower fungal diversity may be a common characteristic in ecosystems dominated with hyphae. For example, Voronina et al. (2011) and Halsey et al. (2016) observed a lower fungal diversity in the mycorrhizospheres of Amanita and Laccaria $[33,34]$. By contrast, Maŕi et al. (2020) found a higher fungal diversity in the fairy ring zone than in outside in grassland [35]. These inconsistent results may be explained by the idea that ecological and environmental conditions are the main driver for the variability in the microbial interactions within fairy rings [36]. This alteration of fungal diversity and simplification of soil fungal community composition in the shiro soil suggests that the hyphae of T. matsutake may shape a specific niche differently from the bulk soil.

\subsection{T. matsutake Associated Fungal Community Similarities in the Shiro Soil across Geographic Locations}

We found that fungal taxa interacting with $T$. matsutake were selectively enriched or reduced in the shiro in comparison to non-shiro soil. For example, members of the genus Lactarius became the largest group in the shiro soil, followed by Russula. These taxa were stimulated by the potential mycorrhizal-helper bacteria [37]. However, it was still unclear whether this alteration in the fungal community composition is related to the growth of T. matsutake. If the fungal community associated with T. matsutake in the shiro is unique and is shared through geographic locations, the T. matsutake domination may cause spatially distinct microbial community composition to be more similar. The fungal community structure in the shiro soil from five forest types in our case was similar (Figure S3), which indicates that soil fungi communities were shaped by the T. matsutake.

Although the species composition of fungi between forest types were similar, we found that forest types significantly changed the relative abundances of specific species. Different soils with five forest types sharing 55 fungal OTUs, potentially resulted in consistent fungal community composition, which may be attributed to the dominance of T. matsutake. Fungal species dissimilarity might be a result of distinctive plant communities. Considering that Pinus yunnanensis, Quercus guyavefolia, and Pinus armandii Franch were not classified as the same genus, they were expected to have a different genetic relationship in phylogenesis, which may form specific niches with physio-chemical properties caused by different litter quality and biomass, root exudates, and nutrient uptake ability [38,39]. 
This was indicated by the significant difference in $\mathrm{pH}$, TC and TN between forest types (Figure 1; Table 3). For example, soil acidity seems to have a species-specific effect on the hyphal growth [40]. $\mathrm{pH}$ affects the growth capacity, mycelial density, colonization capabilities of mycorrhizal species [41]. Alteration in fungal performance under different $\mathrm{pH}$ influences their competitive abilities [42], affecting their abundance in the whole microbial communities. As a consequence, distinctive plant communities exert effects on soil fungal communities.

Our results also show that fungal species have distinct environmental requirements across five forest types, which is consistent with Shi et al. (2014) who suggested that soil fungal distribution is coincident with environmental pattern [43]. Among the five forest types, chemical sources and sinks (i.e., quality and quantity of litters, root exudates) differed to select spatial heterogeneity in which a variety of heterogeneous niches formed. In summary, we found a significant effect of T. matsutake, but in a limited area and also with interactions with other factors, such as local soil chemical properties and plant diversities.

\subsection{Fungal Interaction Shape Fungal Community across Landscape}

Interestingly, there were only 94 kinds of fungi, which accounted for $6.74 \%$ of the total fungi we found in this case, that were correlated with T. matsutake. This was in accordance with Bending et al. (2002) who found that most microorganisms had several lifestyles, such as accompanying or competing with ECM fungi under different environments [44]. Although Mortierella is a frequently reported genus associated with T. matsutake in the shiro, roots, and fruiting bodies [5,45], it was negatively correlated with the abundance of T. matsutake, which was accordance with Vaario et al. (2011) [4]. The exact mechanism of the suppression effect of T. matsutake on Mortierella may be that antibiotics secreted by fungal metabolites limit the ability of SAP fungi (i.e., Mortierella) as mentioned above [30]. Besides, the genus Helotiales was also negatively correlated with T. matsutake. Although Helotiales can form mycorrhizal association (i.e., ECM and ericoid fungi) with hosts to transfer $\mathrm{C}$ and nutrients [46], T. matsutake may colonize the root tips faster, which exhibited a priority effect and led to divergent communities because of the competition for limited root tips [47]. On the other hand, Helotiales sp. had diverse lifestyles, such as mycorrhizalforming, ectomycorrhizal parasites, as well as saprobes, which was dependent on the local environmental conditions [48]. Thus, this may explain the decreased abundance of Helotiales in our case compared to the increased abundance in other studies.

However, the genus Oidiodendron, one kind of typical ECM fungi, collaborated with T. matsutake in five different forest soils. This was in accordance with Bending et al. (1997) who found that Oidiodendron could increase $\mathrm{C}$ and $\mathrm{N}$ availability in the rhizosphere by the stimulation of lignin degradation and litter decomposition [49], due to the increased exudation of cellulase and chitinase, consequently providing necessary nutrients that mitigate the nutritional deficiency of T. matsutake and facilitates its growth. Overall, the selection of these taxa may be related to competition for resources and space as well as their different nutrient strategies in the rhizosphere.

Information to interpret the mechanisms of the above noted dominance effect of T. matsutake on the associated fungal groups is still limited. The differential flow of $\mathrm{C}$ from ECM fungi to the other fungal groups may be a possible explanation for the multiple fungal performances. It has been extensively reported that energy-rich exudates from mycorrhizal fungi sustains the growth of other associated fungi [50]. However, plants can restrict the amount of $C$ available to fungi according to the nutrient quantities they are receiving from it when co-colonized fungal species existed [51]. This would play a large role in the outcome of ECM competition growth because of the symbiotic interaction with hosts which are not $C$ limited [47]. Besides C, T. matsutake may also exploit and immobilize minerals, thus causing a nutrient deficiency for coexisting microbial communities [27]. In addition to competition, associated fungal communities may also be influenced by mycotoxins such as cyanuric compounds or complex chemical compounds with phytotoxic and antimicrobial abilities produced by ECM mycelium [52]. This is consistent with previous studies who showed 
the negative effects of ECM fungi on other microbial communities [53]. For example, T. matsutake fruit bodies secrete hydrogen peroxide as a predominant inhibitor of other fungal growth [25]. Alternatively, the sandy soil that dominated in the shiro soil provides more oxygen and less moisture and nutrients than non-shiro soil, which may be an important selection tool for the associated fungal community $[45,54]$.

\section{Conclusions}

Overall, our findings highlight that T. matsutake causes a lower fungal diversity and simplifies the fungal community composition in shiro soil compared with non-shiro soil across five forest types, which results from a direct selection effect of T. matsutake (e.g., competition for space and nutrients as indicated by lower TN). We also found that geographical proximity was accompanied by a similar fungal community structure but different contributions from specific species under five forest types, suggesting that the T. matsutake associated fungal communities were selected not only from the dominance of T. matsutake but also from the local soil properties and plant diversity. Among the fungi coexisting with T. matsutake, Oidiodendron were found to collaborate with T. matsutake in samples from all forest sites, whereas Helotiales and Mortierella showed a negative correlation with it. The selection of these taxa may be related to their ability to compete with resources and different nutrient strategists in the soil. Overall, our study suggests multiple symbiotic relationships between microbes and T. matsutake, which may form distinct fungal communities.

Supplementary Materials: The following are available online at https: / www.mdpi.com/article / 10.3390/biology10101051/s1, Figure S1 Location of the study site. The circles indicate the position of Deqing (DQ1, DQ2), Lijing (LJ), Baoshan (BS) and Chuxiong (CX) in Yunnan, South-western China. Figure S2 The relative abundance of Tricholoma in Deqing (DQ1, DQ2), Lijing (LJ), Baoshan (BS) and Chuxiong (CX) in Yunnan, South-western China. Figure S3 Two-dimensional nonmetric multidimensional scaling (NMDS) ordination of fungal communities in shiro (S) and non-shiro (ns) soil in Deqing (DQ1, DQ2), Lijing (LJ), Baoshan (BS) and Chuxiong (CX) in Yunnan, South-western China. Figure S4 Venn diagram showing the specific and shared OTUs of shiro soil from Deqing (DQ1, DQ2), Lijing (LJ), Baoshan (BS) and Chuxiong (CX). Table S1 The tree diversity (Tree_H), richness (Tree-S), DBH (unit: $\mathrm{m}$ ) and height (High, unit: $\mathrm{m}$ ), and the diversity and richness of tree colonized by ectomycorrhizal fungi (ECMtree_H, ECMtree_S), as well as the diversity and richness of shrub and grass (Shrub_H, Shrub_S, Grass_H, Grass_S) in the Deqing (DQ1, DQ2), Lijing (LJ), Baoshan (BS) and Chuxiong (CX). One-way ANOVA was used to evaluate the effect of forest types on plant diversity and richness. Table S2 The effects of Shiro, forest type and their interactions on soil fungal richness, Fisher- $\alpha$ diversity and Pielou evenness. Table S3 Permutational analysis of variance (PERMANOVA) of total fungi and fungal trophic groups in all forest types.

Author Contributions: Data curation: J.Z., H.G. and L.S.; formal analysis, J.Z. and H.G.; funding acquisition, X.Y., H.G.; methodology, S.Y. and X.Y.; resources, X.Y.; supervision, X.Y. and L.S.; visualization, J.Z. and H.G.; writing-review and editing, J.Z., H.G., X.Y. and L.S. All authors have read and agreed to the published version of the manuscript.

Funding: This study was funded by the Southeast Asia Biodiversity Research Institute, Chinese Academy of Sciences (Grant No. Y4ZK111B01) and the National Natural Science Foundation of China (Grant No. 31370513) from Xuefei Yang. Heng Gui would like to thank the support from the National Natural Science Foundation of China (Grant No. 32001296) and Yunnan Fundamental Research Projects (Grant No. 2019FB063).

Institutional Review Board Statement: Not applicable.

Informed Consent Statement: Not applicable.

Data Availability Statement: The data in this study are readily available upon reasonable request to the corresponding author. BioSample accessions SAMN18710742 to SAMN18710833 have been published.

Conflicts of Interest: There is no conflict of interest to declare. 


\section{References}

1. Ogawa, M. Microbial ecology of mycorrhizal fungus Tricholoma matsutake Ito et Imai (Sing.) in pine forest, I. Fungal colony (Shiro) of T. matsutake. Bull. Gov. For. Exp. Stn. 1975, 272, 79-121. (In Japanese with English Abstract)

2. Yamanaka, T.; Ota, Y.; Konno, M.; Kawai, M.; Ohta, A.; Neda, H.; Terashima, Y.; Yamada, A. The host ranges of conifer-associated Tricholoma matsutake, Fagaceae-associated T. bakamatsutake and T. fulvocastaneum are wider in vitro than in nature. Mycology 2014, 106, 397-406. [CrossRef]

3. Lian, C.; Narimatsu, M.; Nara, K.; Hogetsu, T. Tricholoma matsutake in a natural Pinus densiflora forest: Correspondence between above- and below-ground genets, association with multiple host trees and alteration of existing ectomycorrhizal communities. New Phytol. 2006, 171, 825-836. [CrossRef] [PubMed]

4. Vaario, L.M.; Fritze, H.; Spetz, P.; Heinonsalo, J.; Hanajik, P.; Pennanen, T. Tricholoma matsutake dominates diverse microbial communities in different forest soils. Appl. Environ. Microbiol. 2011, 77, 8523-8531. [CrossRef] [PubMed]

5. Kataoka, R.; Siddiqui, Z.A.; Kikuchi, J.; Ando, M.; Sriwati, R.; Nozaki, A.; Futai, K. Detecting nonculturable bacteria in the active mycorrhizal zone of the pine mushroom Tricholoma matsutake. J. Microbiol. 2012, 50, 199-206. [CrossRef] [PubMed]

6. Kim, M.; Yoon, H.; You, Y.-H.; Kim, Y.-E.; Woo, J.-R.; Seo, Y.; Lee, G.-M.; Kim, Y.J.; Kong, W.-S.; Kim, J.-G. Metagenomic analysis of fungal communities inhabiting the fairy ring zone of Tricholoma matsutake. J. Microbiol. Biotechnol. 2013, 23, 1347-1356. [CrossRef]

7. Oh, S.Y.; Fong, J.J.; Park, M.S.; Lim, Y.W. Distinctive feature of microbial communities and bacterial functional profiles in Tricholoma matsutake dominant soil. PLoS ONE 2016, 11, e0168573. [CrossRef]

8. Vaario, L.-M.; Yang, X.; Yamada, A. Biogeography of the Japanese Gourmet Fungus, Tricholoma matsutake: A Review of the Distribution and Functional Ecology of Matsutake. In Biogeography of Mycorrhizal Symbiosis. Ecological Studies (Analysis and Synthesis); Tedersoo, L., Ed.; Springer: Cham, Switzerland, 2017; Volume 230.

9. Yamanaka, T.; Yamada, A.; Furukawa, H. Advances in the cultivation of the highly-prized ectomycorrhizal mush-room Tricholoma matsutake. Mycoscience 2020, 61, 49-57. [CrossRef]

10. Oh, S.Y.; Park, M.S.; Lim, Y.W. The influence of microfungi on the mycelial growth of ectomycorrhizal fungus Tricholoma matsutake. Microorganisms 2019, 7, 169. [CrossRef]

11. Dudnik, A.; Bigler, L.; Dudler, R. Production of Proteasome Inhibitor Syringolin A by the Endophyte Rhizobium sp. Strain AP16. Appl. Environ. Microbiol. 2014, 80, 3741-3748. [CrossRef]

12. Leake, J.R.; Donnelly, D.P.; Boddy, L. Interactions between ecto-mycorrhizal and saprotrophic fungi. In Mycorrhizal Ecology; van der Heijden, M.G.A., Sanders, I.R., Eds.; Springer: Berlin/Heidelberg, Germany, 2003; pp. 345-372.

13. Summerbell, R.C. From Lamarckian fertilizers to fungal castles: Recapturing the pre-1985 literature on endophytic and saprotrophic fungi associated with ectomycorrhizal root systems. Stud. Mycol. 2005, 53, 191-256. [CrossRef]

14. Leake, J.; Johnson, D.; Donnelly, D.; Muckle, G.; Boddy, L.; Read, D. Networks of power and influence: The role of mycorrhizal mycelium in controlling plant communities and agroecosystem functioning. Can. J. Bot. 2004, 82, 1016-1045. [CrossRef]

15. Philippot, L.; Raaijmakers, J.M.; Lemanceau, P.; van der Putten, W. Going back to the roots: The microbial ecology of the rhizosphere. Nat. Rev. Microbiol. 2013, 11, 789-799. [CrossRef] [PubMed]

16. Bardgett, R.D.; Van der Putten, W.H. Soil biodiversity and ecosystem functioning. Nature 2014, 515, 505-511. [CrossRef]

17. Christ, S.; Wubet, T.; Theuerl, S.; Herold, N.; Buscot, F. Fungal communities in bulk soil and stone compartments of different forest and soil types as revealed by a barcoding ITS rDNA and a functional laccase encoding gene marker. Soil Biol. Biochem. 2011, 43, 1292-1299. [CrossRef]

18. Peay, K.G.; Baraloto, C.; Fine, P.V.A. Strong coupling of plant and fungal community structure across western Amazonian rainforests. ISME J. 2013, 7, 1852-1861. [CrossRef] [PubMed]

19. Frostegård, Å.; Bååth, E.; Tunlio, A. Shifts in the structure of soil microbial communities in limed forests as revealed by phospholipid fatty acid analysis. Soil Biol. Biochem. 1993, 25, 723-730. [CrossRef]

20. Zelles, L. Fatty acid patterns of phospholipids and lipopolysaccharides in the characterisation of microbial communities in soil: A review. Biol. Fertil. Soils 1999, 29, 111-129. [CrossRef]

21. Zhou, J.; Wen, Y.; Shi, L.; Marshall, M.R.; Kuzyakov, Y.; Blagodatskaya, E.; Zang, H. Strong priming of soil organic matter induced by frequent input of labile carbon. Soil Biol. Biochem. 2021, 152, 108069. [CrossRef]

22. Yang, T.; Adams, J.M.; Shi, Y.; He, J.S.; Jing, X.; Chen, L.; Tedersoo, L.; Chu, H. Soil fungal diversity in natural grass-lands of the Tibetan plateau: Associations with plant diversity and productivity. New Phytol. 2017, 215, 756-765. [CrossRef]

23. Smith, S.E.; Read, D. Mycorrhizal Symbiosis, 3rd ed.; Academic Press: London, UK, 2008; pp. 1-787.

24. Zhou, J.; Zang, H.; Loeppmann, S.; Gube, M.; Kuzyakov, Y.; Pausch, J. Arbuscular mycorrhiza enhances rhizodeposition and reduces the rhizosphere priming effect on the decomposition of soil organic matter. Soil Biol. Biochem. 2020, 140, 107641. [CrossRef]

25. Nouri, E.; Breuillin-Sessoms, F.; Feller, U.; Reinhardt, D. Phosphorus and Nitrogen Regulate Arbuscular Mycorrhizal Symbiosis in Petunia hybrida. PLoS ONE 2014, 9, e90841. [CrossRef]

26. Zotti, M.; De Filippis, F.; Cesarano, G.; Ercolini, D.; Tesei, G.; Allegrezza, M.; Giannino, F.; Mazzoleni, S.; Bonanomi, G. One ring to rule them all: An ecosystem engineer fungus fosters plant and microbial diversity in a Mediterranean grassland. New Phytol. 2020, 227, 884-898. [CrossRef]

27. Cairney, J.W.; Meharg, A.A. Interactions between ectomycorrhizal fungi and soil saprotrophs: Implications for decomposition of organic matter in soils and degradation of organic pollutants in the rhizosphere. Can. J. Bot. 2002, 80, 803-809. [CrossRef] 
28. Bödeker, I.T.M.; Lindahl, B.D.; Olson, Å.; Clemmensen, K.E. Mycorrhizal and saprotrophic fungal guilds compete for the same organic substrates but affect decomposition differently. Funct. Ecol. 2016, 30, 1967-1978. [CrossRef]

29. Takakura, Y. Tricholoma matsutake fruit bodies secrete hydrogen peroxide as a potent inhibitor of fungal growth. Can. J. Microbiol. 2015, 61, 447-450. [CrossRef] [PubMed]

30. Tedersoo, L.; Jairus, T.; Horton, B.M.; Abarenkov, K.; Suvi, T.; Saar, I.; Kõljalg, U. Strong host preference of ectomy-corrhizal fungi in a Tasmanian wet sclerophyll forest as revealed by DNA barcoding and taxon-specific primers. New Phytol. 2008, 180, 479-490. [CrossRef]

31. Bennett, L.T.; Kasel, S.; Tibbits, J. Woodland trees modulate soil resources and conserve fungal diversity in fragmented landscapes. Soil Biol. Biochem. 2009, 41, 2162-2169. [CrossRef]

32. Millard, P.; Singh, B.K. Does grassland vegetation drive soil microbial diversity? Nutr. Cycl. Agroecosyst. 2009, 88, 147-158. [CrossRef]

33. Voronina, E.Y. Effect of the mycorrhizosphere on soil micromycete biodiversity and community structure and its relation to the rhizosphere and hyphosphere effects. Microbiology 2011, 80, 584-590. [CrossRef]

34. Halsey, J.A.; de Cássia Pereira e Silva Silva, M.; Andreote, F.D. Bacterial selection by mycospheres of Atlantic Rainforest mushrooms. Antonie Van Leeuwenhoek 2016, 109, 1353-1365. [CrossRef]

35. Marí, T.; Castaño, C.; Rodríguez, A.; Ibáñez, M.; Lobo, A.; Sebastià, M. Fairy rings harbor distinct soil fungal com-munities and high fungal diversity in a montane grassland. Fungal Ecol. 2020, 47, 100962. [CrossRef]

36. Yang, C.; Zhang, F.; Liu, N.; Hu, J.; Zhang, Y. Changes in soil bacterial communities in response to the fairy ring fungus Agaricus gennadii in the temperate steppes of China. Pedobiologia 2018, 69, 34-40. [CrossRef]

37. Li, B.; Ravnskov, S.; Xie, G.; Larsen, J. Differential effects of Paenibacillus spp. on cucumber mycorrhizas. Mycol. Prog. 2008, 7, 277-284. [CrossRef]

38. Gobran, G.; Clegg, S.; Courchesne, F. Rhizospheric Processes Influencing the Biogeochemistry of Forest Ecosystems. Biogeochemistry 1998, 42, 107-120. [CrossRef]

39. Mitchell, R.; Campbell, C.D.; Chapman, S.J.; Osler, G.H.R.; Vanbergen, A.J.; Ross, L.C.; Cameron, C.M.; Cole, L. The cascading effects of birch on heather moorland: A test for the top-down control of an ecosystem engineer. J. Ecol. 2007, 95, 540-554 [CrossRef]

40. Agerer, R.; Taylor, A.F.S.; Treu, R. Effects of acid irrigation and liming on the production of fruit bodies by ectomy-corrhizal fungi. Plant Soil 1998, 199, 83-89. [CrossRef]

41. Courty, P.-E.; Pritsch, K.; Schloter, M.; Hartmann, A.; Garbaye, J. Activity profiling of ectomycorrhiza communities in two forest soils using multiple enzymatic tests. New Phytol. 2005, 167, 309-319. [CrossRef]

42. McAfee, B.; Fortin, J.A. The influence of $\mathrm{pH}$ on the competitive interactions of ectomycorrhizal mycobionts under field conditions. Can. J. For. Res. 1987, 17, 859-864. [CrossRef]

43. Shi, L.-L.; Mortimer, P.E.; Slik, J.W.F.; Zou, X.-M.; Xu, J.; Feng, W.-T.; Qiao, L. Variation in forest soil fungal diversity along a latitudinal gradient. Fungal Divers. 2014, 64, 305-315. [CrossRef]

44. Bending, G.D.; Poole, E.J.; Whipps, J.M. Characterisation of bacteria from Pinus sylvestris-Suillus luteus mycorrhizas and their effects on root-fungus interactions and plant growth. FEMS Microbiol. Ecol. 2002, 39, 219-227. [CrossRef]

45. Li, Q.; Chen, C.; Penttinen, P.; Xiong, C.; Zheng, L.; Huang, W. Microbial diversity associated with Tricholoma matsutake fruiting bodies. Microbiology 2016, 85, 531-539. [CrossRef]

46. Grelet, G.A.; Johnson, D.; Paterson, E.; Anderson, I.C.; Alexander, I.J. Reciprocal carbon and nitrogen transfer between an ericaceous dwarf shrub and fungi isolated from Piceirhiza bicolorata ectomycorrhizas. New Phytol. 2009, 182, 359-366. [CrossRef] [PubMed]

47. Kennedy, P.G.; Hortal, S.; Bergemann, S.E.; Bruns, T.D. Competitive interactions among three ectomycorrhizal fungi and their relation to host plant performance. J. Ecol. 2007, 95, 1338-1345. [CrossRef]

48. Wang, Z.; Binder, M.; Schoch, C.; Johnston, P.R.; Spatafora, J.W.; Hibbett, D.S. Evolution of helotialean fungi (Leotiomycetes, Pezizomycotina): A nuclear rDNA phylogeny. Mol. Phylogenet. Evol. 2006, 41, 295-312. [CrossRef]

49. Bending, G.; Read, D.J. Lignin and soluble phenolic degradation by ectomycorrhizal and ericoid mycorrhizal fungi. Mycol. Res. 1997, 101, 1348-1354. [CrossRef]

50. Vandenkoornhuyse, P.; Mahe, S.; Ineson, P.; Staddon, P.; Ostle, N.; Cliquet, J.-B.; Francez, A.-J.; Fitter, A.H.; Young, P. Active root-inhabiting microbes identified by rapid incorporation of plant-derived carbon into RNA. Proc. Natl. Acad. Sci. USA 2007, 104, 16970-16975. [CrossRef]

51. Nehls, U.; Grunze, N.; Willman, M.; Reich, M.; Kuster, H. Sugar for my honey: Carbohydrate partitioning inectomy-corrhizal symbiosis. Phytochemistry 2007, 68, 82-91. [CrossRef]

52. Blenis, P.V.; Chow, P.S.; Duncan, I.; Knowles, N.R. Cyanide levels near fairy rings affect the growth of grasses and fungi. Can. J. Bot. 2004, 82, 1324-1329. [CrossRef]

53. Frey-Klett, P.; Garbaye, J.; Tarkka, M. The mycorrhiza helper bacteria revisited. New Phytol. 2007, 176, 22-36. [CrossRef]

54. Lisboa, F.J.G.; Chaer, G.; Fernandes, M.F.; Berbara, R.L.L.; Madari, B. The match between microbial community structure and soil properties is modulated by land use types and sample origin within an integrated agroecosystem. Soil Biol. Biochem. 2014, 78, 97-108. [CrossRef] 